\title{
Avaliação de substratos para inoculação micorrízica e aclimatização de dois porta-enxertos de videira micropropagados ${ }^{(1)}$
}

\author{
Josy Moraes Zemke ${ }^{(2)}$, Fabiane Pereira ${ }^{(2)}$, Paulo Emílio Lovato ${ }^{(2)}$ e Aparecido Lima da Silva ${ }^{(2)}$
}

\begin{abstract}
Resumo - O objetivo deste trabalho foi selecionar substratos favoráveis à associação micorrízica na produção de mudas micropropagadas de porta-enxertos de videira. Os porta-enxertos SO4 e Paulsen 1103 foram aclimatizados por três semanas em bandejas alveoladas, contendo seis substratos (à base de solo, composto termofílico, casca de arroz carbonizada, vermiculita, areia e um substrato comercial), com e sem inoculação micorrízica. No final da aclimatização e dez semanas depois, avaliaram-se a colonização micorrízica, a matéria seca de parte aérea e o comprimento radicular das plantas. A intensidade de colonização micorrízica variou em razão dos porta-enxertos e dos substratos utilizados na aclimatização, havendo interação significativa entre os dois fatores. O substrato comercial proporcionou a maior produção de biomassa, mas promoveu a menor colonização micorrízica em todos os porta-enxertos. As combinações mais favoráveis de produção de biomassa vegetal e de taxa de colonização micorrízica ocorreram no porta-enxerto Paulsen 1103, no substrato à base de solo, composto termofílico e areia e, no porta-enxerto $\mathrm{SO} 4$, no substrato à base de solo, composto termofílico e vermiculita.
\end{abstract}

Termos para indexação: Vitis, micorriza, muda, micropropagação, biomassa.

\section{Evaluation of substrates for mycorrhization and weaning of two micropropagated grapevine rootstocks}

\begin{abstract}
The aim of this work was to select substrates conductive to the establishment of arbuscular mycorrhizas in the production of micropropagated grapevine rootstocks. Micropropagated SO4 and Paulsen 1103 rootstock plantlets were weaned for three weeks in trays with mycorrhizal fungalinoculated or uninoculated substrates (prepared with soil, compost, calcined rice hulls, vermiculite and sand, besides a commercial substrate). At the end of the weaning period and ten weeks after, shoot and root growth and mycorrhizal root colonization were evaluated. Mycorrhizal root colonization varied according to the rootstock and substrates, with a significant interaction between these factors. The commercial substrate was associated with the highest increase in shoot and root mass, but it decreased mycorrhizal colonization. The best substrate for Paulsen 1103 rootstock growth and mycorrhizal inoculation was prepared with soil, compost and sand and, for the SO4 rootstock the substrate prepared with soil, compost and vermiculite.
\end{abstract}

Index terms: Vitis, micorrhizae, planting stock, micropropagation, biomass.

\section{Introdução}

As técnicas de cultura in vitro de tecidos vegetais têm importância para a multiplicação de porta-

(1)Aceito para publicação em 12 de agosto de 2003.

Extraído da dissertação de mestrado apresentada pela primeira autora à Universidade Federal de Santa Catarina (UFSC), Florianópolis, SC. Apoio financeiro da Fapergs.

(2)UFSC, Centro de Ciências Agrárias, Dep. de Engenharia Rural, Caixa Postal 476, CEP 88034-001 Florianópolis, SC. E-mail: josymoraes@bol.com.br, fabiane.pereira@bol.com.br, plovato@mbox1.ufsc.br, alsilva@mbox1.ufsc.br enxertos de fruteiras (Grattapaglia \& Machado, 1998). O sucesso da multiplicação depende da aclimatização, uma fase delicada para plantas micropropagadas (Vidal et al., 1992; Hooker et al., 1994). Nessa etapa, a inoculação de fungos micorrízicos arbusculares (FMA) é uma medida importante, visto que as micorrizas são uma associação mutualística que pode garantir a sobrevivência e o crescimento das plantas (Vestberg \& Estaún, 1997; Saggin Júnior \& Lovato, 1999).

As micorrizas contribuem para o crescimento da videira por meio do aumento da biomassa vegetal e da distribuição da biomassa entre a parte aérea e a 
raiz (Schubert et al., 1990). Os fungos micorrízicos arbusculares influenciam a morfogênese e a arquitetura das raízes de plantas de videira micropropagadas, assegurando uma rápida formação e melhor desenvolvimento do sistema radicular depois do transplante (Schellenbaum et al., 1991). Além disso, os FMA têm importância no controle biológico de nematóides, de fungos e de bactérias que causam doenças vegetais (Azcón-Aguilar \& Barea, 1996). No caso da videira, o patógeno de soloFusariumoxysporumf. $\mathrm{sp}$. herbemontis - que ataca o sistema radicular de porta-enxertos suscetíveis, como os de cultivares Vitis riparia $\mathrm{x}$ Vitis berlandieri - tem causado sérios prejuízos nas regiões vitícola de Santa Catarina e Rio Grande do Sul (Gricoletti Júnior, 1993). Métodos biológicos, como o uso dos FMA, oferecem alternativa promissora aos métodos químicos com vistasao controle desses patógenos (Utkhede \& Smith, 2000).

A inoculação micorrízica é, em geral, mais eficiente que o uso de substratos com alta fertilidade para promover o crescimento das plantas após o transplante e em condições desfavoráveis (Estaún et al., 1999). Além disso, as micorrizas podem reduzir o estresse do transplante e atuar como controle biológico, além de facilitar a adaptação das plantas às condições de campo, principalmente as perenes, como as frutíferas (Lindermann \& Davis, 2001).

Os fungos micorrízicos arbusculares também podem influenciar na morfogênese e na arquitetura das raízes de plantas de videira micropropagada, assegurando uma rápida formação e melhor desenvolvimento do sistema radicular depois do transplante (Schellenbaum et al., 1991). Por essas razões, é desejável obterem-se níveis altos de colonização micorrízica em mudas de plantas.

Para promover a micorrização de plantas durante a aclimatização, devem ser consideradas as características física e química do substrato utilizado, que afetam a sobrevivência das plantas e a instalação de micorrizas arbusculares. Os principais fatores que afetam a micorrização são a aeração, oteor de matéria orgânica e a disponibilidade de nutrientes, especialmente o fósforo (Gaur \& Adholeya, 2000).

$\mathrm{Na}$ micropropagação comercial de fruteiras, geralmente não se utilizam substratos à base de solo, a fim de se evitarem problemas com patógenos. Em substratos comerciais, ricos em N, P e K, formulados para garantir o crescimento das plantas, os FMA apresentam pequeno potencial de infecção e lento desenvolvimento, e consequentemente, limitado efeito sobre o crescimento das plantas (Smith \& Read, 1997). O efeito benéfico da presença de solo na composição do substrato para o desenvolvimento de micorrizas e desenvolvimento das plantas micropropagadas foi constatado por Vidal et al. (1992). No entanto, constatou-se que a micorrização em macieiras micropropagadas pode ser obtida em substratos comerciais ricos em nutrientes (Schubert \& Lubraco, 2000).

A interação entre os FMA e os substratos tem sido avaliada em várias espécies micropropagadas (Vestberg, 1992; Wang et al., 1993; Estaún et al., 1999), pois a composição do substrato ideal pode variar em função da espécie de FMA e da planta aclimatizada.

O objetivo deste trabalho foi selecionar substratos favoráveis à associação micorrízica na produção de mudas micropropagadas de porta-enxertos de videira.

\section{Material e Métodos}

Os porta-enxertos de videira Paulsen 1103 e SO4 foram micropropagados em meio de cultura DSD1 (Silva \& Doazan, 1995) com sacarose $\left(20,0 \mathrm{~g} \mathrm{~L}^{-1}\right)$ e ágar-ágar (5,5 $\left.\mathrm{g} \mathrm{L}^{-1}\right)$, isento de reguladores de crescimento e com pH 6,4. Os frascos foram mantidos durante 60 dias a $25 \pm 1^{\circ} \mathrm{C}$, fotoperíodo de 16 horas e radiação fotossinteticamente ativa de 40 a $45 \mu \mathrm{mol} \mathrm{m}^{-2} \mathrm{~s}^{-1}$ no nível do frasco, com umidade relativa do ar de 60 a $70 \%$. Para a aclimatização dos porta-enxertos foram realizadas podas conservando três folhas basais e 1,0 a $1,5 \mathrm{~cm}$ de raiz.

O experimento, um fatorial $2 \times 6$, foi composto dos tratamentos de inoculação (inoculação micorrízica e nãomicorrízica) e de seis substratos: Nitossolo Vermelho distroférrico, composto termofílico e vermiculita, na proporção de 2:3:3; Nitossolo Vermelho distroférrico, composto termofílico e casca de arroz carbonizada (3:1:1); Nitossolo Vermelho distroférrico, composto termofílico e areia (1:1:1); Nitossolo Vermelho distroférrico e composto termofílico $(3: 2,5)$; Nitossolo Vermelho distroférrico e vermiculita (2:3); e do substrato comercial Plantmax ${ }^{\circledR}$, constituído de mistura de cascas de árvore, turfa, vermiculita e calcário. As características químicas dos substratos estão descritas na Tabela 1.

Utilizou-se um delineamento completamente casualizado, com 6 repetições. Cada porta-enxerto recebeu 2,0 g de inóculo micorrízico, constituído de uma mistura de Glomus etunicatum, G. clarum eAcaulospora sp., multiplicados em vasos com Paspalum notatum var. 
saurae. Os substratos, exceto o substrato comercial, foram desinfestados por 10 minutos em forno de microondas e distribuídos em bandejas de polipropileno com alvéolos de $20 \mathrm{~cm}^{3}$. A microbiota não-micorrízica do solo foi obtida por meio da suspensão de $40 \mathrm{~g}$ de inóculo em $1 \mathrm{~L}$ de água destilada. Após agitação intensa, a suspensão foi passada em papel-filtro e adicionou-se $1 \mathrm{~mL}$ do filtrado a cada alvéolo no tratamento não-micorrizado correspondente. Para aclimatização, os porta-enxertos foram transferidos às bandejas colocadas em caixas cobertas com uma lâmina de vidro de $3 \mathrm{~mm}$.

A partir do décimo quinto dia houve a abertura progressiva do vidro a fim de aclimatizar as plantas à atmosfera ambiente. Após três semanas, metade das plantas foi transferida para vasos individuais de $400 \mathrm{~cm}^{3}$, contendo os mesmos tratamentos, e mantidos por dez semanas em sala de crescimento, a $26 \pm 2^{\circ} \mathrm{C}$, fotoperíodo de 16 horas e radiação fotossinteticamente ativa de $150 \mu \mathrm{mol} \mathrm{m}^{-2} \mathrm{~s}^{-1}$. Todas as plantas receberam água destilada diariamente $e$ semanalmente aplicaram-se $5 \mathrm{~mL}$ de solução nutritiva de Long Ashton (Resh, 1997) com 10\% da concentração original de fósforo.

Ao final das três semanas de aclimatização e das dez semanas em sala de crescimento após a aclimatização, foram determinados peso da matéria seca de parte aérea, comprimento radicular e colonização micorrízica. Também foram determinados os conteúdos de $\mathrm{P}$ foliar, após dez semanas em câmara de crescimento. Essas determinações e as análises químicas dos substratos foram realizadas pela Faculdade de Agronomia - Departamento de Solos UFRGS. O comprimento das raízes foi avaliado pela técnica da grade quadriculada (Tennant, 1975). A fórmula utilizada foi $\mathrm{R}=\mathrm{N}$ x fator de conversão $(0,7857)$, em que $\mathrm{N}$ é o número de interseções de raizes com a quadrícula da placa. A intensidade de colonização micorrízica foi avaliada pela técnica de Trouvelot et al. (1986), após descoloração das raízes em KOH $10 \%$ e coloração com azul de tripano em glicerol acidificado (Koske \& Gemma, 1989). Os dados foram submetidos à análise de variância (programa StatGraphics, versão 7.0) e as médias foram comparadas pelo teste de Newmann-Keuls, a 5\% de probabilidade.

\section{Resultados e Discussão}

A análise da variância mostrou que em ambos porta-enxertos houve efeito dos dois fatores, inoculação micorrízica e substrato, e interação significativa entre eles, no acúmulo de matéria seca da parte aérea, no final da aclimatização. Na segunda avaliação, dez semanas após a aclimatização, não houve interação entre os fatores. Ocorreu efeito apenas dos substratos sobre a matéria seca da parte aérea e o comprimento radicular (Tabela 2 ).

A produção de matéria seca de parte aérea do porta-enxerto Paulsen 1103, no final da aclimatização,

Tabela 1. Teores de carbono orgânico, $\mathrm{pH}, \mathrm{Al}$, macro e micronutrientes em substratos usados na aclimatização e no cultivo de porta-enxertos micropropagados de videira.

\begin{tabular}{|c|c|c|c|c|c|c|c|c|c|c|}
\hline Substrato $^{(1)}$ & $\begin{array}{c}\mathrm{C} \\
\left(\mathrm{g} \mathrm{kg}^{-1}\right) \\
\end{array}$ & $\mathrm{pH}$ & $\begin{array}{c}\mathrm{Al} \\
-\end{array}$ & $\begin{array}{l}\mathrm{Ca} \\
\mathrm{mmol}\end{array}$ & $\begin{array}{l}\mathrm{Mg} \\
\left.\mathrm{m}^{-3}\right)-\end{array}$ & $\begin{array}{c}\mathrm{P} \\
--- \\
\end{array}$ & $\mathrm{K}$ & Mn & $\begin{array}{c}\mathrm{Zn} \\
\left.\mathrm{Im}^{-3}\right) \\
\end{array}$ & $\mathrm{Cu}$ \\
\hline NCA & 44 & 5,9 & 0 & 100 & 31 & 375 & 290 & 6 & 16,0 & 0,3 \\
\hline $\mathrm{NCV}$ & 42 & 5,3 & 2 & 120 & 75 & 179 & 250 & 16 & 13,0 & 0,5 \\
\hline NCCAC & 31 & 5,0 & 3 & 85 & 30 & 145 & 251 & 32 & 15,0 & 0,7 \\
\hline $\mathrm{NC}$ & 49 & 5,5 & 0 & 130 & 43 & 202 & 258 & 20 & 19,0 & 0,3 \\
\hline NV & 6 & 4,8 & 16 & 24 & 24 & 10 & 74 & 11 & 0,7 & 2,2 \\
\hline Substrato comercial & 200 & 5.9 & 0 & 410 & 240 & 792 & 1.800 & 4 & 8,4 & 0,1 \\
\hline
\end{tabular}

(1)NCA: solo, composto e areia; NCV: solo, composto e vermiculita; NCCAC: solo, composto e casca de arroz carbonizada; NC: solo e composto, NV: solo e vermiculita.

Tabela 2. Massa de matéria seca de parte aérea (MSA) e comprimento radicular do porta-enxerto Paulsen 1103 micorrizado (MIC) ou não-micorrizado (NM), cultivado em seis substratos ${ }^{(1)}$.

\begin{tabular}{|c|c|c|c|c|c|c|c|c|c|c|c|c|}
\hline \multirow[t]{3}{*}{ Substrato $^{(2)}$} & \multicolumn{6}{|c|}{$\operatorname{MSA}\left(\mathrm{g}\right.$ planta $\left.{ }^{-1}\right)$} & \multicolumn{6}{|c|}{ Comprimento radicular $(\mathrm{cm})$} \\
\hline & \multicolumn{3}{|c|}{$\begin{array}{c}\text { Final da } \\
\text { aclimatizacão }\end{array}$} & \multicolumn{3}{|c|}{$\begin{array}{c}\text { Dez semanas após } \\
\text { aclimatização }\end{array}$} & \multicolumn{3}{|c|}{$\begin{array}{c}\text { Final da } \\
\text { aclimatizacão }\end{array}$} & \multicolumn{3}{|c|}{$\begin{array}{c}\text { Dez semanas após } \\
\text { aclimatizacão }\end{array}$} \\
\hline & NM & MIC & Média & NM & MIC & Média & NM & MIC & Média & NM & MIC & Média \\
\hline NCA & $0,035 \mathrm{~A}$ & $0,035 \mathrm{~A}$ & $0,035 b$ & 1,118 & 1,319 & $1,218 \mathrm{c}$ & 18 & 22 & $20 \mathrm{a}$ & 624 & 642 & $633 c$ \\
\hline $\mathrm{NCV}$ & $0,038 \mathrm{~A}$ & $0,040 \mathrm{~A}$ & $0,039 \mathrm{a}$ & 1,641 & 1,704 & $1,672 b$ & 18 & 19 & $18 \mathrm{a}$ & 736 & 1.116 & $926 b$ \\
\hline NCCAC & $0,032 \mathrm{~A}$ & $0,030 \mathrm{~A}$ & $0,031 \mathrm{~b}$ & 0,579 & 0,805 & $0,692 d$ & 23 & 23 & $23 \mathrm{a}$ & 479 & 713 & $596 \mathrm{c}$ \\
\hline $\mathrm{NC}$ & $0,033 \mathrm{~B}$ & $0,040 \mathrm{~A}$ & $0.036 \mathrm{ab}$ & 1,061 & 0,608 & $0,834 \mathrm{~cd}$ & 17 & 16 & $16 \mathrm{a}$ & 683 & 521 & $602 c$ \\
\hline NV & $0,018 \mathrm{~B}$ & $0,025 \mathrm{~A}$ & $0,021 \mathrm{c}$ & 0,298 & 0,079 & $0,188 \mathrm{e}$ & 16 & 13 & $14 \mathrm{a}$ & 489 & 196 & $342 d$ \\
\hline Substrato comercial & $0.030 \mathrm{~A}$ & $0.035 \mathrm{~A}$ & $0.032 b$ & 2.229 & 2.144 & $2.186 \mathrm{a}$ & 19 & 25 & $22 \mathrm{a}$ & 1.233 & 1.596 & $1.414 \mathrm{a}$ \\
\hline Médias & 0,031 & 0,034 & & 1,154 & 1,109 & & 18 & 20 & & 707 & 797 & \\
\hline
\end{tabular}


variou em função do substrato e da presença dos FMA, com interação significativa entre os dois fatores (Tabela 2). Nessa etapa, houve resposta à inoculação em termos de crescimento da parte aérea desse porta-enxerto aclimatizado nos substratos à base de solo e composto (NC) e de solo com vermiculita $(\mathrm{NV})$. Dez semanas após a inoculação, houve efeito apenas dos substratos, e os maiores acúmulos de matéria seca foram observados no substrato comercial, seguido pelo substrato à base de solo, composto e vermiculita (NCV). No final da aclimatização, o comprimento radicular do porta-enxerto não foi afetado pela presença dos FMA ou pelos substratos, mas houve efeito dos substratos na segunda avaliação, com os maiores valores ocorrendo no substrato comercial.

As porcentagens de colonização micorrízica foram diferentes em razão dos substratos (Tabela 3 ). Os maiores valores no porta-enxerto Paulsen 1103 ocorreram nos substratos NCA, NC e NV, no final da aclimatização. Esse comportamento modificou-se após o período seguinte, em câmara de crescimento, quando os índices de colonização diminuíram ou mantiveram-se baixos, exceto no substrato à base de solo e vermiculita (NV), no qual a intensidade de colonização aumentou em $150 \%$. Os níveis relativamente baixos de matéria orgânica e de nutrientes disponíveis (Tabela 1) e a boa porosidade e aeração do substrato NV devem ter favorecido a colonização micorrízica. No entanto, este substrato proporcionou menor crescimento de plantas (Tabela 4). Isso está relacionado aos valores mais baixos de $\mathrm{pH}$, e conseqüente aumento nos teores de Al trocável desse substrato, que também tem teores menores de $\mathrm{P}$ e potássio. As condições adversas inibiram a resposta à inoculação, visto que a presença de micorrizas contribui para o aumento no crescimento de mudas de videira em substratos semelhantes (Schubert et al., 1990; Lindermann \& Davis, 2001).

A associação micorrízica é afetada pela espécie ou cultivar da planta, pelo isolado do fungo micorrízico e pelas características do substrato (Vestberg, 1992; Estaún et al., 1999). Tal fato foi observado no porta-enxerto Paulsen 1103, pois a interação entre substrato e colonização micorrízica foi significativa quanto ao crescimento da parte aérea, na fase de aclimatização. Posteriormente, as condições de solo impediram a expressão de efeitos da associação micorrízica. A ausência de resposta do crescimento das plantas à inoculação também pode estar ligada à baixa porcentagem de arbúsculos, que foi sempre abaixo de $1 \%$ no Paulsen 1103. A luminosidade relativamente baixa da câmara de crescimento pode ter provocado essa ocorrência de poucos arbúsculos. No entanto, também deve considerar-se que o efeito das micorrizas sobre o crescimento vegetal na aclimatização - fase crítica para a sobrevivência e estabelecimento das plantas - atenua-se, ou mesmo desaparece nas etapas posteriores de produção das mudas (Vidal et al., 1992; AzcónAguilar \& Barea, 1997; Estaún et al., 1999).

O porta-enxerto SO4 apresentou os maiores acúmulos de matéria seca da parte aérea, no final da aclimatização, no substrato comercial, e o menor crescimento de parte aérea ocorreu no substrato de solo e vermiculita (NV) (Tabela 4). A presença dos FMA causou redução no peso de matéria seca de parte aérea do porta-enxerto $\mathrm{SO} 4$ nos substratos com vermiculita (NCV e NV). Dez semanas após a aclimatização, o maior acúmulo de matéria seca da parte aérea ocorreu também no substrato comercial,

Tabela 3. Índices de colonização (\%) micorrízica de mudas dos porta-enxertos Paulsen 1103 e SO4 em seis substratos, no final e dez semanas após a aclimatização ${ }^{(1)}$.

\begin{tabular}{|c|c|c|c|c|}
\hline \multirow[t]{2}{*}{ Substratos $^{(2)}$} & \multicolumn{2}{|c|}{ Paulsen 1103} & \multicolumn{2}{|c|}{$\mathrm{SO} 4$} \\
\hline & $\begin{array}{c}\text { No final da } \\
\text { aclimatização }\end{array}$ & $\begin{array}{l}\text { Dez semanas após } \\
\text { aclimatização }\end{array}$ & $\begin{array}{c}\text { No final da } \\
\text { aclimatização }\end{array}$ & $\begin{array}{l}\text { Dez semanas após } \\
\text { aclimatização }\end{array}$ \\
\hline$\overline{\mathrm{NCA}}$ & $14 \mathrm{a}$ & $8 b$ & $34,0 \mathrm{a}$ & $27 b$ \\
\hline $\mathrm{NCV}$ & $2 c$ & $3 \mathrm{c}$ & $27,0 \mathrm{a}$ & $25 b$ \\
\hline NCCAC & $5 b$ & $7 b$ & $11,0 \mathrm{~b}$ & $27 b$ \\
\hline $\mathrm{NC}$ & $11 \mathrm{a}$ & $1 d$ & $16,0 \mathrm{~b}$ & $4 \mathrm{~d}$ \\
\hline NV & $10 \mathrm{a}$ & $25 \mathrm{a}$ & $0,3 \mathrm{~d}$ & $73 a$ \\
\hline Substrato comercial & $2 \mathrm{c}$ & $2 \mathrm{c}$ & $9,0 \mathrm{c}$ & $11 \mathrm{c}$ \\
\hline
\end{tabular}

${ }^{(1)}$ Médias seguidas da mesma letra, em cada coluna, não diferem entre si pelo teste de Newmann-Keuls. ${ }^{(2)}$ NCA: solo, composto e areia; NCV: solo, composto e vermiculita; NCCAC: solo, composto e casca de arroz carbonizada; NC: solo e composto; NV: solo e vermiculita. 
e o substrato com solo, composto e vermiculita (NCV), ainda que inferior ao material comercial, foi superior aos demais substratos. O crescimento de raízes não foi afetado por nenhum dos fatores na saída da aclimatização mas, dez semanas depois, apresentou um comportamento semelhante ao da parte aérea, com os maiores valores no substrato comercial, seguido pelo substrato NCV.

Nos porta-enxertos SO4, o substrato NCA também promoveu a maior taxa de colonização micorrízica na aclimatização (Tabela 3). É importante que o substrato usado para o crescimento de mudas micropropagadas favoreça a associação micorrízica e o crescimento vegetal (Wang et al., 1993). Plantas micorrizadas terão melhor desenvolvimento do sistema radicular após o transplante e menor mortalidade, e há efeito da simbiose na proteção das plantas contra patógenos do solo (Azcón-Aguilar \& Barea, 1996; Pozo et al., 2002).

A adição de solo na formulação do substrato geralmente resulta em níveis altos de colonização micorrízica (Vidal et al., 1992), mas outros componentes também podem ter efeitos significativos. A adição de composto termofílico nos substratos aumentou os valores de $\mathrm{P}, \mathrm{K}$ e do $\mathrm{pH}$ (Tabela 1), e, conseqüentemente, nesses substratos ocorreram o maior crescimento das plantas e a menor colonização micorrízica. O inverso foi observado nas plantas cultivadas no substrato à base de solo e vermiculita $(\mathrm{N}: \mathrm{V})$, que não continha composto. Deste modo, para essas plantas cultivadas nos substratos formulados com composto, os efeitos benéficos da associação micorrízica podem aparecer num estágio mais prolongado de desenvolvimento, visto que na produ- ção de porta-enxertos de videira a micorrização é importante, não somente para a promoção de crescimento, mas também para proteger as plantas do ataque de patógenos de solo, como Fusarium oxysporum $\mathrm{f}$. sp. herbemontis.

Substratos à base de solo são recomendados por promover a colonização micorrízica, e por terem custo baixo, quando comparados aos substratos comerciais usados na aclimatização de plantas micropropagadas (Saggin Júnior \& Lovato, 1999). Na micropropagação comercial de frutíferas utilizamse, normalmente, substratos ricos em matéria orgânica, os quais possuem alta concentração de nutrientes, com vistas a promover crescimento rápido e alta taxa de sobrevivência das plantas. Entretanto, esses substratos têm efeito negativo no estabelecimento das micorrizas, causando baixos índices de colonização radicular (Smith \& Read, 1997). A combinação contendo apenas solo e composto termofílico (NC) resultou em um substrato pouco poroso, com aeração pobre. O crescimento das plantas e a colonização micorrízica podem ter sido limitados por aeração insuficiente, pois baixas concentrações de $\mathrm{O}_{2}$ inibem severamente a germinação dos esporos e a colonização das raízes (Gaur \& Adholeya, 2000). Um aspecto a ser considerado na formulação de substratos é a variação no teor de composto termofílico, a fim de atingir um conjunto de características físicas e químicas que favoreçam, ao mesmo tempo, o crescimento das mudas e o estabelecimento das micorrizas.

O substrato comercial proporcionou, nos dois porta-enxertos, valores de peso da matéria seca de parte aérea e comprimento radicular maiores que os demais substratos, na avaliação feita dez semanas após aclimatização (Tabelas 2 e 4). No entanto, nesse

Tabela 4. Massa de matéria seca de parte aérea (MSA) e comprimento radicular do porta enxerto SO4 micorrizado (MIC) ou não-micorrizado (NM), cultivado em seis substratos ${ }^{(1)}$.

\begin{tabular}{|c|c|c|c|c|c|c|c|c|c|c|c|c|}
\hline \multirow[t]{3}{*}{ Substrato $^{(2)}$} & \multicolumn{6}{|c|}{ MSA (g planta $\left.{ }^{-1}\right)$} & \multicolumn{6}{|c|}{ Comprimento radicular $(\mathrm{cm})$} \\
\hline & \multicolumn{3}{|c|}{$\begin{array}{c}\text { Final da } \\
\text { aclimatizacão }\end{array}$} & \multicolumn{3}{|c|}{$\begin{array}{l}\text { Dez semanas após } \\
\text { aclimatização }\end{array}$} & \multicolumn{3}{|c|}{$\begin{array}{c}\text { Final da } \\
\text { aclimatizacão }\end{array}$} & \multicolumn{3}{|c|}{$\begin{array}{l}\text { Dez semanas após } \\
\text { aclimatização }\end{array}$} \\
\hline & $\mathrm{NM}$ & $\mathrm{MIC}$ & Média & $\mathrm{NM}$ & $\mathrm{MIC}$ & Média & $\mathrm{NM}$ & MIC & Média & $\mathrm{NM}$ & MIC & Média \\
\hline NCA & $0,047 \mathrm{~A}$ & $0,035 \mathrm{~A}$ & $0,041 \mathrm{~b}$ & 1,194 & 1,352 & $1,273 \mathrm{c}$ & 20 & 21 & $20 \mathrm{a}$ & 602 & 916 & $759 \mathrm{c}$ \\
\hline $\mathrm{NCV}$ & $0,053 \mathrm{~A}$ & $0,038 \mathrm{~B}$ & $0,045 b$ & 1,890 & 1,857 & $1,873 \mathrm{~b}$ & 20 & 22 & $21 \mathrm{a}$ & 1.293 & 1.395 & $1.344 b$ \\
\hline NCCAC & $0,045 \mathrm{~A}$ & $0,030 \mathrm{~A}$ & $0,037 \mathrm{~b}$ & 0,617 & 0,691 & $0,654 \mathrm{c}$ & 23 & 20 & $22 \mathrm{a}$ & 756 & 791 & $774 \mathrm{c}$ \\
\hline $\mathrm{NC}$ & $0,065 \mathrm{~A}$ & $0,032 \mathrm{~B}$ & $0,048 \mathrm{~b}$ & 1,084 & 1,142 & $1,113 \mathrm{c}$ & 31 & 19 & $25 \mathrm{a}$ & 759 & 854 & $806 \mathrm{c}$ \\
\hline NV & $0,033 \mathrm{~A}$ & $0,017 \mathrm{~B}$ & $0,025 \mathrm{c}$ & 0,229 & 0,113 & $0,171 \mathrm{~d}$ & 21 & 25 & $23 \mathrm{a}$ & 402 & 194 & $298 d$ \\
\hline Substrato comercial & $0.043 \mathrm{~B}$ & $0.067 \mathrm{~A}$ & $0.055 \mathrm{a}$ & 2.105 & 2226 & $2.165 \mathrm{a}$ & 21 & 26 & $24 \mathrm{a}$ & 1743 & 1729 & $1736 \mathrm{a}$ \\
\hline Média & 0.047 & 0.031 & & 1186 & 1230 & & 23 & 22 & & 926 & 980 & - \\
\hline
\end{tabular}


substrato, as plantas tiveram baixa colonização micorrízica (Tabela 3), por causa dos altos níveis de nutrientes disponíveis (Tabela 1), principalmente o $\mathrm{P}$, que inibe a colonização micorrízica e afeta a resposta em crescimento das plantas (Smith \& Read, 1997).

\section{Conclusões}

1. A biomassa vegetal e a taxa de colonização micorrízica do porta-enxerto Paulsen 1103 são beneficiadas pelo substrato à base de solo, composto termofílico e areia.

2. A biomassa vegetal e a taxa de colonização micorrízica do porta-enxerto SO4 são beneficiadas pelo substrato à base de solo, composto termofílico e vermiculita.

3. O substrato comercial aumenta a biomassa vegetal e diminui a colonização micorrízica.

\section{Referências}

AZCÓN-AGUILAR, C.; BAREA, J. M. Applying mycorrhizal biotechnology to horticulture: significance and potentials. Scientia Horticulturae, Amsterdam, v. 68, p. 1-24, 1997.

AZCÓN-AGUILAR, C.; BAREA, J. M. Arbuscular mycorrhizal and biological control of soil-borne plant pathogens: an overview of the mechanisms involved. Mycorrhiza, New York, v. 6, p. 457-464, 1996.

ESTAÚN, V.; CALVET, C.; CAMPRUÍ, A.; PINOCHET, J. Long-term effects of nursery start substrate and AM inoculation of micropropagated peach $\mathrm{x}$ almond hybrid rootstock GF 677. Agronomie, Paris, v. 19, p. 483-489, 1999

GAUR, A.; ADHOLEYA, A. Effects of the particle size of soil-less substrates upon AM fungus inoculum production. Mycorrhiza, New York, v. 10, n. 1, p. 43-48, 2000 .

GRATTAPAGLIA, D.; MACHADO, M. A. Micropropagação. In: TORRES, A. C.; CALDAS, L. S.; BUSO, J. A. Cultura de tecidos e transformação genética de plantas. Brasília: Embrapa-CNPH, 1998. v. 1, p. $183-261$.

GRICOLETTI JÚNIOR, A. Fusariose da videira: resistência de cultivares, sintomas e controle. Bento Gonçalves: Embrapa-CNPUV, 1993. 19 p. (Circular Técnica, 18).
HOOKER, J. E.; GIANINAZZI, S.; VESTBERG, M.; BAREA, J. M.; ATKINSON, D. The applications of arbuscular mycorrhizal fungi to micropropagated systems: an opportunity to reduce inputs. Agricultural Science in Finland, Jokioinen, v. 3, p. 227-232, 1994.

KOSKE, R. E.; GEMMA, J. N. A modified procedure for staining roots to detect VA mycorrhizas. Mycological Research, New York, v. 92, p. 39-48, 1989.

LINDERMANN, R. G.; DAVIS, A. Comparative response of selected grapevine rootstocks and cultivars to inoculation with different mycorrhizal fungi. American Journal of Enology and Viticulture, Davis, v. 52, p. 8$11,2001$.

POZO, M. J.; CORDIER, C.; DUMAS-GAUDOT, E.; GIANINAZZI, S.; BAREA, J. M.; AZCÓN-AGUILAR, C. Localized versus systemic effect of arbuscular mycorrhizal fungi on defense responses to Phythophtora infection in tomato plants. Journal of Experimental Botany, Oxford, v. 53, n. 3/8, p. 525-534, 2002.

RESH, H. M. Cultivos hidropónicos: nuevas técnicas de producción. 4. ed. Madrid: Mundi-Prensa Libros, 1997. $509 \mathrm{p}$.

SAGGIN JÚNIOR, O. J.; LOVATO, P. E. Aplicação de micorrizas arbusculares na produção de mudas e plantas micropropagadas. In: SIQUEIRA, J. O.; MOREIRA, F. M. S.; LOPES, A. S.; GUILHERME, L. R. L.; FAQUIM, V. Inter-relação fertilidade, biologia do solo e nutrição de plantas, Viçosa, MG: Sociedade Brasileira de Ciência do Solo/Ufla, 1999. p. 725-773.

SCHELLENBAUM, L.; BERTA, G.; RAVOLANIRINA, F.; TISSERANT, B.; GIANINAZZI, S.; FITTER, A. H. Influence of endomycorrhizal infection on root morphology in a micropropagated woody plant species (Vitis vinifera L.). Annals of Botany, London, v. 68, p. 135-141, 1991.

SCHUBERT, A.; LUBRACO, G. Mycorrhizal inoculation enhances growth and nutrient uptake of micropropagated apple rootstocks during weaning in commercial substrates of high nutrient availability. Applied Soil Ecology, Amsterdam, v. 15, n. 2, p. 113-118, 2000.

SCHUBERT, A.; MAZZITELI, M.; ARIUSSO, O.; EYNARD, I. Effects of vesicular arbuscular mycorrhizal fungi on micropropagated grapevine: influence of endophyte strain, P fertilization and growth medium. Vitis, Siebeldingen, v. 29, p. 5-13, 1990. 
SILVA, A. L. da; DOAZAN, J. P. Une méthode d'irradiation aux rayons gamma appliquée à des portegreffes de vigne in vitro. Journal International des Sciences de la Vigne et du Vin, Bordeaux, v. 29, p. 1-9, 1995.

SMITH, S. E.; READ, D. J. Mycorrhizal symbiosis. 2nd ed. Cambridge, England: Academic, 1997. 589 p.

TENNANT, D. A test of a modified line intersect method of estimating root length. Journal of Ecology, Oxford, v. 63 , p. $995-1004,1975$.

TROUVELOT, A.; KOUGH, J. L.; GIANINAZZIPEARSON, V. Mesure du taux de mycorhization VA d'un système radiculaire. Recherche de méthodes d'estimation ayant une signification fonctionnelle. In: GIANINAZZI, S.; GIANINAZZI-PEARSON, V. (Ed.). Mycorhizes: physiologie et génétique, Dijon: Institut National de la Recherche Agronomique, 1986. p. 217-220.

UTKHEDE, R. S.; SMITH, E. M. Impact of chemical, biological and cultural treatments on the growth and yield of apple in replant-disease soil. Australasian Plant Pathology, Collingwood, v. 29, n. 2, p. 129-136, 2000.
VESTBERG, M. The effect of growth substrate and fertilizer on the growth and vesicular arbuscular mycorrhizal infection of three hosts. Agricultural Science in Finland, Jokioinen, v. 1, p. 95-105, 1992.

VESTBERG, M.; ESTAÚN, V. Micropropagated plants: an opportunity to positive manage mycorrhizal activities. In: GIANINAZZI, S.; SHÜEPP, H. Impact of arbuscular mycorrhizas on sustainable agriculture and natural ecosystems. Basel: Birkhauser, 1997. p. 217-226.

VIDAL, M. T.; AZCÓN-AGUILAR, C.; BAREA, J. M.; PLIEGO-ALFARO, F. Mycorrhizal inoculation enhances growth and development of micropropagated plants of avocado. HortScience, Amsterdam, v. 27, n. 7, p. 785787, 1992.

WANG, H.; PARENT, S.; GOSSELIN, A.; DESJARDINS, Y. Vesicular-arbuscular mycorrhizal peat-based substrates enhance symbiosis establishment and growth of three micropropagated species. Journal of the American Society for Horticultural Science, Alexandria, v. 118, n. 6, p. 896-901, 1993. 